\title{
Observação, em sala de aula, do comportamento de alunos em processo de aquisição de leitura e escrita por equivalência
}

\author{
José Gonçalves Medeiros \\ Analu Regis Fernandes \\ Raquel Pimentel \\ Ana Carolina Seara Simone \\ Universidade Federal de Santa Catarina
}

\begin{abstract}
Resumo
A sala de aula, enquanto contexto de ensino, pode configurar-se como local apropriado para a observação das relações professor-aluno, bem como das demais variáveis que interferem no processo ensino-aprendizagem. Para verificar os efeitos de um procedimento de ensino computadorizado, foram realizadas observações da interação professor-aluno em uma sala de aula de uma escola da rede pública antes e depois da aplicação do mesmo. Os comportamentos acadêmicos e não acadêmicos dos alunos e da professora foram observados, tendo por base algumas categorias comportamentais. Através dessas observações, pôde-se perceber que não houve uma correlação direta entre o desempenho no procedimento computadorizado e alteração no desempenho (aumento do percentual dos comportamentos acadêmicos, do contato com a professora, entre outros) das crianças em sala de aula. Apesar disso, esse tipo de procedimento propõe-se a verificar mudanças que vão além das encontradas em situações experimentais controladas do laboratório.
\end{abstract}

Palavras-chave: Observação; sala de aula; relação professor-aluno.

\section{Abstract \\ Classroom observation of students behavior in reading and writing acquisition processes by equivalence}

The classroom, whilst in a teaching contest, can be locally configured as an appropriate place for observation of the professor-pupil relationship, as well as other variables which interfere with the teaching process and learning. To verify the effects of a computerized teaching procedure, observations [before and after application] were made of interactions in a classroom of the public school system. The academic and non-academic activities of students and teachers were observed, to establish some behavioral categories. Through these observations, it could be noted that there was not a direct correlation between performance according to the computerized procedure and change (percent increase of academic behaviors, of contact with the teacher, among others) of children in classroom. Despite that, this kind of procedure is intended to verify the changes of inter-relationship that are found as a result of controlled experimental situations in the laboratory.

Keywords: Observation; classroom; teacher and student relationship.

A aquisicão do repertório de leitura e escrita nas séries iniciais do primeiro grau tem se mostrado problemática, principalmente para as criancas de classes sociais menos favorecidas, onde os incentivos para a leitura e escrita são quase inexistentes devido, principalmente, ao nível educacional dos pais e às condicões socioeconômicas. Boa parte dessas criancas chega à escola sem ter tido a oportunidade de freaüentar a pré-escola. E uma proporção daquelas que freqüentaram não apresenta os repertórios básicos mínimos necessários para um processo de alfabetização com sucesso. Começam, então, a aparecer os "problemas" para o professor que se vê diante de crianças que não demonstram sucesso no processo de alfabetização.

A tendência da maioria dos professores é de atribuir à criança a culpa pelo fracasso. contribuindo, com isso. para o fortalecimento dos estigmas sociais que. em interacão com outras condiç̃es, acabam por levar a criança a acreditar, de fato, que ela é culpada e incapacitada para aprender. O que se observa, então, é um elevado índice de repetência e evasão escolar. Comecam. assim. a aparecer os alunos com problemas de aprendizaaem nos diagnósticos de psicólogos com formação mais clínica que escolar que, por sua vez, concebem a criança 
como sendo o problema a ser tratado, ou as famílias com suas dinâmicas mal-estruturadas.

Esta visão, porém. não é hegemônica e algumas abordagens teóricas que lidam com estas questões têm produzido conhecimento onde o foco principal é a escola, mais particularmente as relações professor-aluno. comecando no planeiamento e se estendendo até à sala de aula, como afirma D’Oliveira (1987): “...em outras palavras, o que aprendi a ver é que não existem "alunos-problemas" e "professores-problemas". mas a relação entre eles em sala de aula é que provavelmente contém os aspectos problemáticos que reauer atuação imediata e possível dentro da escola" (p. 1).

A concepcão de uma relação recíproca entre professor e aluno pode ser uma maneira para revelar as relacões entre as ocorrências da sala de aula de uma maneira mais precisa. Gil (1990, 1993, 1995) demonstra que não são apenas os alunos que sofrem influência das acões dos professores. mas que as acões dos alunos influenciam também o desempenho do professor em sala de aula.

Possivelmente. uma das maiores dificuldades na relacão professor-aluno reside iustamente no fato do professor atender a um número elevado de alunos. incluindo aí criancas que não possuem familiaridade com o ambiente da sala de aula. o que pode levá-las a apresentar comportamentos não acadêmicos e incompatíveis com a aprendizagem. Boa parte dos professores desconhece a realidade dos alunos e os códigos verbais que trazem para a sala de aula. Além destes aspectos, por terem de lidar com uma quantidade grande de alunos. ficam impossibilitados de dar a atencão necessária e propiciar as contingências reforçadoras no momento adequado.

Medeiros, Teixeira, Cabral. Silva e Brandão (1994b) relatam. em um estudo realizado com uma classe de alunos especiais, que o professor da turma dava mais atenção aos comportamentos inadequados dentro de sala de aula do que àqueles considerados adequados, favorecendo a ocorrência de comportamentos incompatíveis com a aprendizagem. Assim. para controlar o comportamento dos alunos, a professora usava procedimentos coercitivos, aumentando assim a probabilidade de comportamentos de esquiva e fuga dentro desse contexto. E, como a coerção é associada à aprendizagem. os alunos logo aprendem que lazer é incompatível com aprender. No entanto. “(...) aqueles que conduzem os seus alunos com sucesso a cada passo, reforcando positivamente sucessos. em vez de punir fracassos. não criam desistentes: eles não dão aos seus alunos razão para fuair" (Sidman, 1995. D. 119). Num outro estudo. Viecili e Medeiros (2002) relatam o comportamento de coerção dos professores em relação a alunos (com e sem história de fracasso escolar). Os resultados obtidos confirmam a utilizacão diferenciada da coercão com alunos com história de fracasso escolar ao mesmo tempo em que conseqüenciacão positiva foi utilizada com alunos sem história de fracasso escolar.
Para a realização de uma investigacão no contexto de sala de aula. observou-se a relacão estabelecida entre nove alunos das séries iniciais $\left(1^{\mathrm{a}}\right.$ e $\left.2^{\mathrm{a}}\right)$ do ensino público e as respectivas professoras. As criancas escolhidas participavam paralelamente de um procedimento computadorizado com o auxílio de um sofware desenvolvido por Govos e Almeida (1994), denominado Mestre@, que contém recursos motivacionais para a aquisicão de leitura e escrita. A realizacão das observacões tinha o obietivo de verificar a repercussão do procedimento computadorizado no comportamento das crianças em sala de aula.

O desenvolvimento desse procedimento computadorizado relaciona-se teórica e metodologicamente àqueles ${ }^{1}$ que foram realizados nos últimos cinco anos, em que Medeiros, Konescki e Souza (1993) e Medeiros e cols. (1994a) trabalharam com crianças com história de fracasso escolar em um programa de ensino de discriminações condicionais, onde os modelos eram palavras faladas e os estímulos de comparação eram palavras impressas (compostas por duas e por três sílabas). A partir de tais trabalhos, verificou-se um aumento significativo do número de palavras que as crianças passaram a ler em relação ao repertório de entrada, além da emergência de novas relações que surgiram a partir das relações condicionais ensinadas.

Para uma criança com história de fracasso devida, em parte, aos insucessos no processo de aquisição do repertório textual de leitura e escrita, um procedimento desta natureza pode motivá-la (fato que os estudos da área têm demonstrado) a prosseguir na tarefa escolar, o que possivelmente refletiria nas atividades de sala de aula.

\section{Participantes}

\section{MÉTODO}

Nove crianças, denominadas Participantes (Ps ou P), fizeram parte do procedimento de observação em sala de aula. Essas crianças estavam realizando um procedimento computadorizado para alunos com dificuldades relacionadas à aquisição de leitura e escrita de palavras. O grupo foi composto por seis crianças do sexo masculino e três do feminino, com idades entre 6 e 8 anos. São alunos da $1^{\mathrm{a}}$ ( 7 crianças) e $2^{\mathrm{a}}$ ( 2 crianças) séries, provenientes de duas turmas e professoras diferentes, de um colégio estadual do município de Florianópolis, SC. Nenhum dos participantes havia sido reprovado até então.

\section{Material}

Foram utilizados lápis, borracha, uma folha de protocolo para registro dos dados das observações e dois cronômetros. Foi utilizado o registro no formato de tríplice contingência (Matos \& Danna, 1984). As classes de repostas dos Ps foram transcritas na coluna do meio (numa folha dividida em três colunas) e as classes de respostas e ou estímulos dos demais participan- 
tes (professoras) foram registradas nas colunas 1 (condições de estímulos antecedentes) e 3 (condições de estímulos conseqüentes). A técnica de registro utilizada foi a de "Registro de eventos por minuto ou fração de minuto” (Fagundes, 1982, p. 63).

\section{Procedimento}

As observações foram realizadas em sala de aula por duas bolsistas de IC (Iniciação Científica). No registro, foram incluídos os comportamentos dos Ps, bem como os das professoras. Foram realizadas 10 sessões de observação ANTES do início do procedimento experimental computadorizado, no início do ano letivo, e outras 10 sessões DEPOIS do término do procedimento, no final do ano letivo.

O procedimento experimental, utilizado no Laboratório de Informática da escola, foi o desenvolvido por Goyos e Almeida (1994), através de um software desenvolvido por eles. Este procedimento, denominado de exclusão, é usado para expandir gradualmente, ao longo de uma seqüência de passos, o repertório de pareamentos entre modelos e estímulos de comparação. A base desse procedimento consiste na presença, em cada tentativa de pareamento, de um estímulo de comparação conhecido pelo P, que é apresentado juntamente com outro estímulo de comparação, porém desconhecido pelo $\mathrm{P}$.

Antes do início das observações, já definidas as categorias comportamentais, as bolsistas realizaram observações-treino em sala de aula, a fim de alcançarem, no mínimo, 80 por cento de fidedignidade entre elas, ou seja, um grau de concordância minimamente aceito em relação aos registros das categorias comportamentais. As bolsistas permaneciam em sala de aula o tempo suficiente para observar todos os participantes da sala, com duração de 10 minutos de observação para cada P. Os dados foram coletados durante o período de aula, preferencialmente nas aulas de Língua Portuguesa, com exceção das disciplinas de Educação Física e Artes. As categorias de comportamento utilizadas foram as descritas nas Tabelas 1 e 2 .

Cada minuto foi dividido em intervalos de 15 segundos, nos quais 5 segundos foram reservados para a observação do comportamento e 10 segundos para o registro na folha. Foram realizadas duas etapas de observação: uma no início e outra ao final do procedimento.

Tabela 1 - Relação das categorias comportamentais do P com seus respectivos códigos, nomes e descrição

\begin{tabular}{|c|c|c|}
\hline CÓDIGO & NOME & DESCRIÇÃO \\
\hline RT & $\begin{array}{l}\text { Realizar tarefas } \\
\text { escolares }\end{array}$ & $\begin{array}{l}\text { Classes de respostas emitidas, que demonstram o interesse do participante pelos conteúdos e atividades, e a } \\
\text { realização das atividades pelo P dadas pela professora em sala de aula. Por exemplo: ler (em voz alta ou em } \\
\text { silêncio); movimentar-se em busca dos objetos escolares (lápis, borracha, caderno, tubo de cola, tesoura, lápis de } \\
\text { cor, giz de cera, etc.) necessários para a realização da tarefa; responder à chamada; escrever no quadro negro, } \\
\text { livro ou caderno ou olhar para estes; olhar para a professora durante as explicações; ouvir leitura de outrem; } \\
\text { organizar ambiente para estudo (colocar materiais sobre a mesa, carteira, cadeira). }\end{array}$ \\
\hline ICP & $\begin{array}{l}\text { Iniciar contato } \\
\text { com a professora }\end{array}$ & $\begin{array}{l}\text { Classes de respostas emitidas pelo } \mathrm{P} \text {, de interação com a professora, independente da professora responder ou } \\
\text { não: chamar a professora, pedir para ir ao quadro negro, aproximar-se dela, tocá-la, mostrar suas tarefas a ela, } \\
\text { perguntar e falar com a mesma. }\end{array}$ \\
\hline $\mathrm{RCP}$ & $\begin{array}{l}\text { Responder ao } \\
\text { contato da } \\
\text { professora }\end{array}$ & $\begin{array}{l}\text { Classes de respostas emitidas pelo } P \text {, de interação com a professora, que representam a resposta ao contato } \\
\text { iniciado pela professora: ir ao quadro negro a mando da professora, ler em voz alta quando solicitado, entregar } \\
\text { caderno para a correção, responder às perguntas da professora. }\end{array}$ \\
\hline RTC & $\begin{array}{l}\text { Realizar tarefas } \\
\text { com o colega }\end{array}$ & $\begin{array}{l}\text { Classes de respostas emitidas pelo } P \text { de interação com o colega (individual ou em grupo): discutir tarefas ou } \\
\text { conferir exercícios com colegas, explicar atividades e conteúdos para o colega ou receber explicações; emprestar } \\
\text { ou pedir emprestado material escolar necessário à realização da atividade. }\end{array}$ \\
\hline AO & Atender a ordens & $\begin{array}{l}\text { Classes de respostas emitidas pelo } \mathrm{P} \text {, que visam cumprir ordens dadas por outrem: sentar-se, virar para frente, } \\
\text { trocar de carteira, aplaudir. }\end{array}$ \\
\hline AP & $\begin{array}{l}\text { Auxiliar a } \\
\text { professora }\end{array}$ & $\begin{array}{l}\text { Classes de respostas emitidas pelo } P \text { que visam cumprir ordens dadas pela professora com intuito de auxiliá-la: } \\
\text { pegar e distribuir materiais (como agendas, provas, textos), pegar ou levar algo para outra sala (direção, } \\
\text { supervisão). }\end{array}$ \\
\hline $\mathrm{T}$ & Tocar-se & $\begin{array}{l}\text { Classes de respostas emitidas pelo } P \text { que evidenciam contato físico consigo mesmo: coçar-se, chupar o dedo, } \\
\text { mexer no cabelo, manipular qualquer parte do corpo, colocar qualquer objeto na boca (régua, lápis etc...). }\end{array}$ \\
\hline D & Distrair-se & $\begin{array}{l}\text { Classes de respostas emitidas pelo P que demonstram distração durante a realização de tarefas: olhar para lugar } \\
\text { indeterminado, assobiar, mexer no material que não seja necessário para a realização da tarefa; folhear caderno } \\
\text { sem buscar algo específico; ler bilhetes ou outros materiais que não estejam relacionados à atividade executada. }\end{array}$ \\
\hline $\mathbf{R}$ & Recusar & $\begin{array}{l}\text { Classes de respostas que denotam esquiva do } P \text { à realização de qualquer tarefa ou ordem a ser cumprida: } \\
\text { sinalizar com a cabeça ou verbalmente que não vai ao quadro negro, que não quer realizar determinado exercício } \\
\text { ou atividade; que não vai a outra sala de aula, que não vai distribuir materiais; deixar de fazer tarefas de casa ou } \\
\text { ignorar a interação iniciada pela professora. }\end{array}$ \\
\hline
\end{tabular}


Tabela 2 - Relação das categorias comportamentais da professora com seus respectivos códigos, nomes e descrição

\begin{tabular}{|c|c|c|}
\hline CÓDIGO & NOME & DESCRIÇÃO \\
\hline ET & Explicar tarefas & $\begin{array}{l}\text { Classes de respostas emitidas pela professora com a intenção de corrigir e orientar a execução dos } \\
\text { exercícios (coletivamente): explicar o exercício; escrever no quadro negro; escrever no caderno dos Ps } \\
\text { ou colar folha de exercício. }\end{array}$ \\
\hline $\mathrm{ICl}$ & $\begin{array}{l}\text { Iniciar contato individual } \\
\text { com o P }\end{array}$ & $\begin{array}{l}\text { Classes de respostas emitidas pela professora de interação individual com o P: explicar exercício ou } \\
\text { atividade individualmente, pedir caderno para conferir a tarefa, pedir para ler em voz alta, pedir para ir } \\
\text { ao quadro negro, solicitar que o P faça a correção da tarefa em voz alta, fazer perguntas em relação à } \\
\text { atividade ou de cunho pessoal. }\end{array}$ \\
\hline $\mathrm{RC}$ & $\begin{array}{l}\text { Responder à iniciativa de } \\
\text { contato do P }\end{array}$ & $\begin{array}{l}\text { Classes de respostas emitidas pela professora que ocorrem após um contato inicial do P: explicar } \\
\text { exercício ou atividade individualmente, pedir para ler em voz alta, solicitar que o P faça a correção da } \\
\text { tarefa em voz alta, fazer perguntas em relação à atividade ou de cunho pessoal. }\end{array}$ \\
\hline NR & $\begin{array}{l}\text { Não responder à iniciativa } \\
\text { de contato }\end{array}$ & $\begin{array}{l}\text { Classes de respostas emitidas pela professora que representam a ausência de interação após o conta- } \\
\text { to iniciado pelo P: ignorar o P quando o mesmo a solicita, não responder ao P independente de o ter ou } \\
\text { não escutado. }\end{array}$ \\
\hline I & Incentivar & $\begin{array}{l}\text { Classes de respostas emitidas pela professora que consequenciam as respostas dos Ps consideradas } \\
\text { corretas: elogiar o P; confirmar o acerto do exercício. }\end{array}$ \\
\hline $\mathbf{R}$ & Repreender & $\begin{array}{l}\text { Classes de respostas emitidas pela professora que repreendem a ação do } \mathrm{P} \text {, corrigindo (em tom de voz } \\
\text { exacerbada) seus erros e comportamentos inadequados em sala de aula (individual ou coletivo): man- } \\
\text { dar o P ficar quieto, gritar, bater palmas ou objetos para chamar a atenção, chamar (em tom alto e forte) } \\
\text { o nome do P, olhar para o P de forma ofensiva (arregalando os olhos erguendo as sobrancelhas). }\end{array}$ \\
\hline DO & Dar ordens & $\begin{array}{l}\text { Classes de respostas emitidas pela professora que objetivam induzir o } \mathrm{P} \text { a cessar os comportamentos } \\
\text { que possam vir a atrapalhar o desempenho acadêmico e auxiliá-la de um modo geral: mandar virar-se } \\
\text { para frente, mandar sentar-se, mandar trocar de lugar, mandar pegar e distribuir materiais, mandar ir a } \\
\text { outra sala. }\end{array}$ \\
\hline DP & Distrair-se & $\begin{array}{l}\text { Classe de respostas emitidas pela professora que demonstram distração durante o período em que os } \\
\text { Ps estão realizando tarefas: falar com pessoas que chegam a porta, ler ou escrever algo que não } \\
\text { esteja relacionado à atividade acadêmica que esteja sendo realizada, olhar para lugar indeterminado. }\end{array}$ \\
\hline
\end{tabular}

\section{RESULTADOS E DISCUSSÃO}

\section{Comportamentos acadêmicos e não acadêmicos dos Ps (alunos)}

As porcentagens de comportamentos acadêmicos (parte inferior da Figura 1) verificadas antes são inferiores às verificadas depois do procedimento, com exceção dos Ps 4, 5, 6 e 7 em que os valores percentuais são praticamente idênticos. Há também um aumento percentual para os comportamentos não acadêmicos (parte superior da Figura 1) com exceção dos Ps 2, 3, 8 e 9 em que os valores são muito próximos. Em termos comparativos, as porcentagens dos comportamentos acadêmicos são mais altas do que as porcentagens dos comportamentos não acadêmicos.

A média dos comportamentos não acadêmicos antes do procedimento é de $18,5 \%$, enquanto que a média posterior é de $24,72 \%$. Há, portanto, um aumento percentual de ambas as categorias, contudo o aumento é maior para os comportamentos não acadêmicos (de 18 para 24\% aproximadamente) do que para os comportamentos acadêmicos (de 44 para 47\% aproximadamente). Se a diferença percentual entre os acadêmi$\cos (44-47 \%)$ e não acadêmicos (18-24\%) é praticamente o dobro, poder-se-ia supor que a professora deu mais atenção aos acadêmicos do que aos não acadê- micos, não confirmando, portanto, os dados verificados por Medeiros e cols. (1994b), em que o professor da turma dava mais atenção aos comportamentos inadequados dentro de sala de aula do que àqueles considerados adequados, favorecendo a ocorrência de comportamentos incompatíveis com a aprendizagem.

Neste estudo, nenhuma intervenção em sala de aula foi realizada pelos pesquisadores. Apenas observou-se a relação professor-aluno existente. É possível que os Ps do presente estudo que freqüentavam o laboratório de informática e participavam do procedimento experimental tenham, de fato, apresentado algum tipo de generalização em sala de aula.

A ausência de uma diferença percentual sistemática para todos os sujeitos nos impede de afirmar que ela seja uma função única do procedimento experimental de ensino. Pode ser devido, também, ao procedimento de ensino da professora em sala de aula. A observação do desempenho de um grupo controle possivelmente propiciaria informação mais precisa sobre este aspecto. 


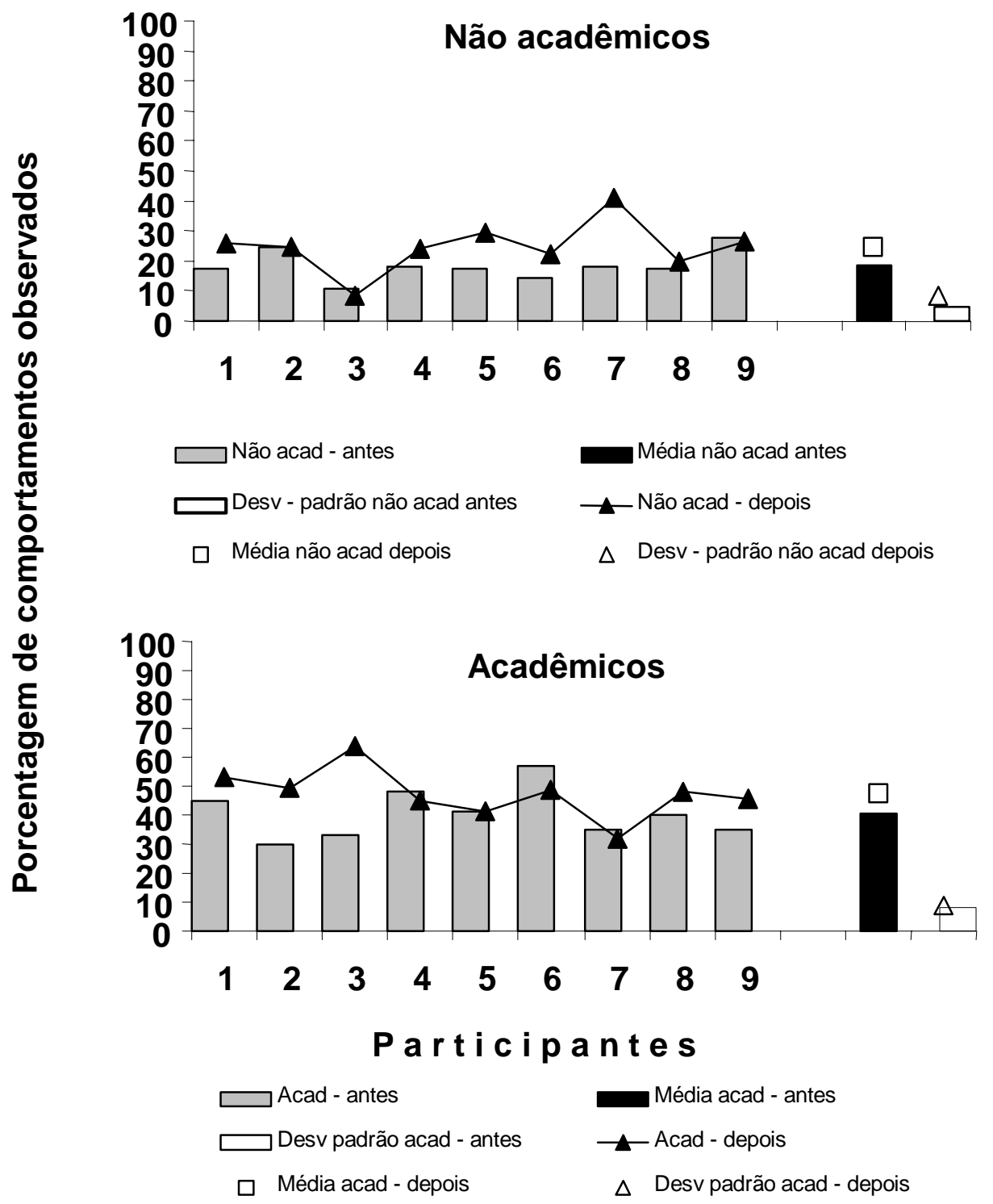

Figura 1. Porcentagem de comportamentos não acadêmicos (relacionar-se com o colega [RC], tocar-se [T], distrair-se [D] e recusar [R]) e acadêmicos (realizar tarefas escolares [RT], iniciar contato com a professora [ICP], responder ao contato da professora [RCP] e realizar tarefas com o colega [RTC]) observados antes do procedimento e após o seu término. Média e desvio padrão de ambos os períodos estão colocados. à direita do histograma.

\section{Comportamentos acadêmicos de explicar tarefas pela professora}

Pode-se observar na Figura 2 que, no início do ano, antes de iniciar o procedimento, a explicação de tarefas pelo professor levou os Ps a realizarem mais freqüentemente tarefas individualmente e junto com colegas do que no final do ano quando a porcentagem diminui (de 20,8 para 9,01, em média), o que indica que estavam mais concentradas no início do ano do que no final. Uma possibilidade para que isso tenha ocorrido é que o período em que foram realizadas as observações após o procedimento coincidiu com o final do ano letivo, quando as atividades estavam mais relacionadas às festividades (Natal) e próximo das férias escolares. Poderia também ser interpretado como independência dos Ps em que realizaram as tarefas sem necessidade de explicação por parte da professora.

No caso do comportamento não acadêmico de distrair-se, após a realização do procedimento, quando a professora explicava tarefas (parte inferior da Figura 2 ), pode-se verificar que, entre os nove Ps, em apenas três Ps (1, 2 e 3$)$ há uma diminuição percentual mais significativa (de 7 para 0,5 para $\mathrm{P} 1$; de 9,75 para 1,5 
para P2 e de 5,5 para 0,5 para P3); para os Ps 4, 8 e 9, a diminuição percentual é mais baixa (de 4,2 para 3,5 para P4; de 4,5 para 2,75 para P8 e de 3 para 2 para P9). Em relação aos Ps 6 e 7, ao contrário dos demais, a porcentagem dos comportamentos não acadêmicos desses Ps aumentou após o procedimento. Esses Ps foram mudados de classe durante o ano letivo em decorrência de licença da professora, o que leva a crer que a presença deles numa turma numerosa tenha favorecido a distração, dificultando a realização de tarefas enquanto a professora as explicava.

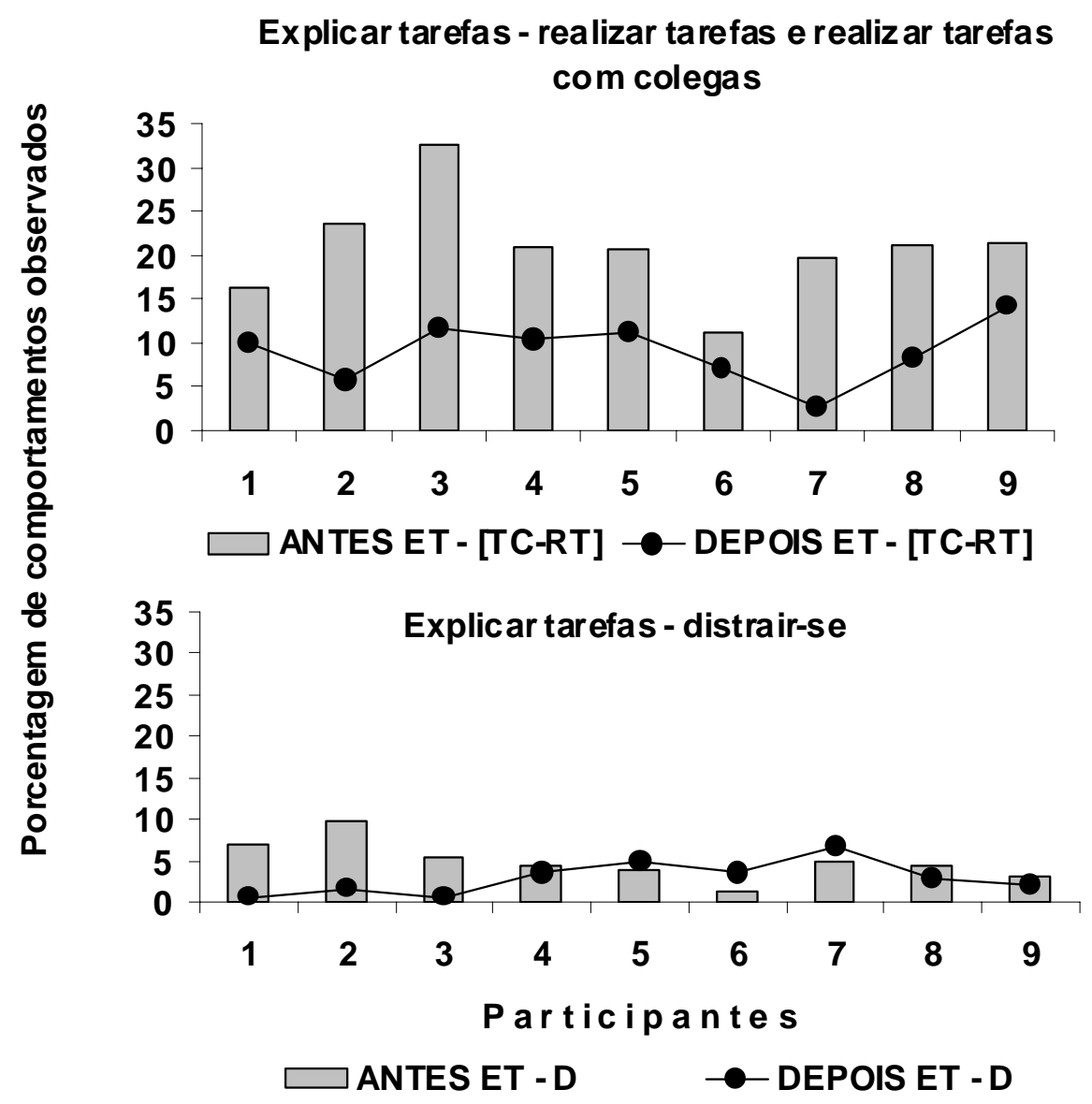

Figura 2 - Comportamento da professora de explicar tarefas. Na parte superior encontra-se a relação entre 0 explicar tarefas e 0 comportamento dos alunos de realizar tarefas individualmente e junto com colegas e, na inferior, o comportamento de distração dos Ps quando a professora explicava tarefas.

\section{Comportamentos não acadêmicos de distrair-se da professora}

Em relação ao comportamento de distração da professora (parte superior da Figura 3), nota-se que alguns Ps (3, 5, 6 e 8) realizaram tarefas mais freqüentemente enquanto a professora estava distraída, ao passo que outros $(1,2,4,7$ e 9$)$ o fizeram com freqüência inferior, tanto antes, quanto depois do procedimento, não se podendo observar qualquer relação sistemática entre um período (antes do procedimento) e outro (depois do procedimento). Em relação aos Ps 6 e 7 (que foram transferidos de uma classe para outra no meio do ano) verifica-se um aumento percentual do comportamento de realizar tarefas individualmente e junto com colegas no final do ano.

Na relação observada entre o comportamento de distrair-se da professora e distrair-se dos Ps, nota-se que os Ps 1 e 5 distraíram-se mais antes do que depois do procedimento. $\mathrm{O}$ inverso pode ser observado em relação ao comportamento dos Ps 6 e 7 (que foram transferidos de sala) em que se distraíram mais depois do procedimento. 


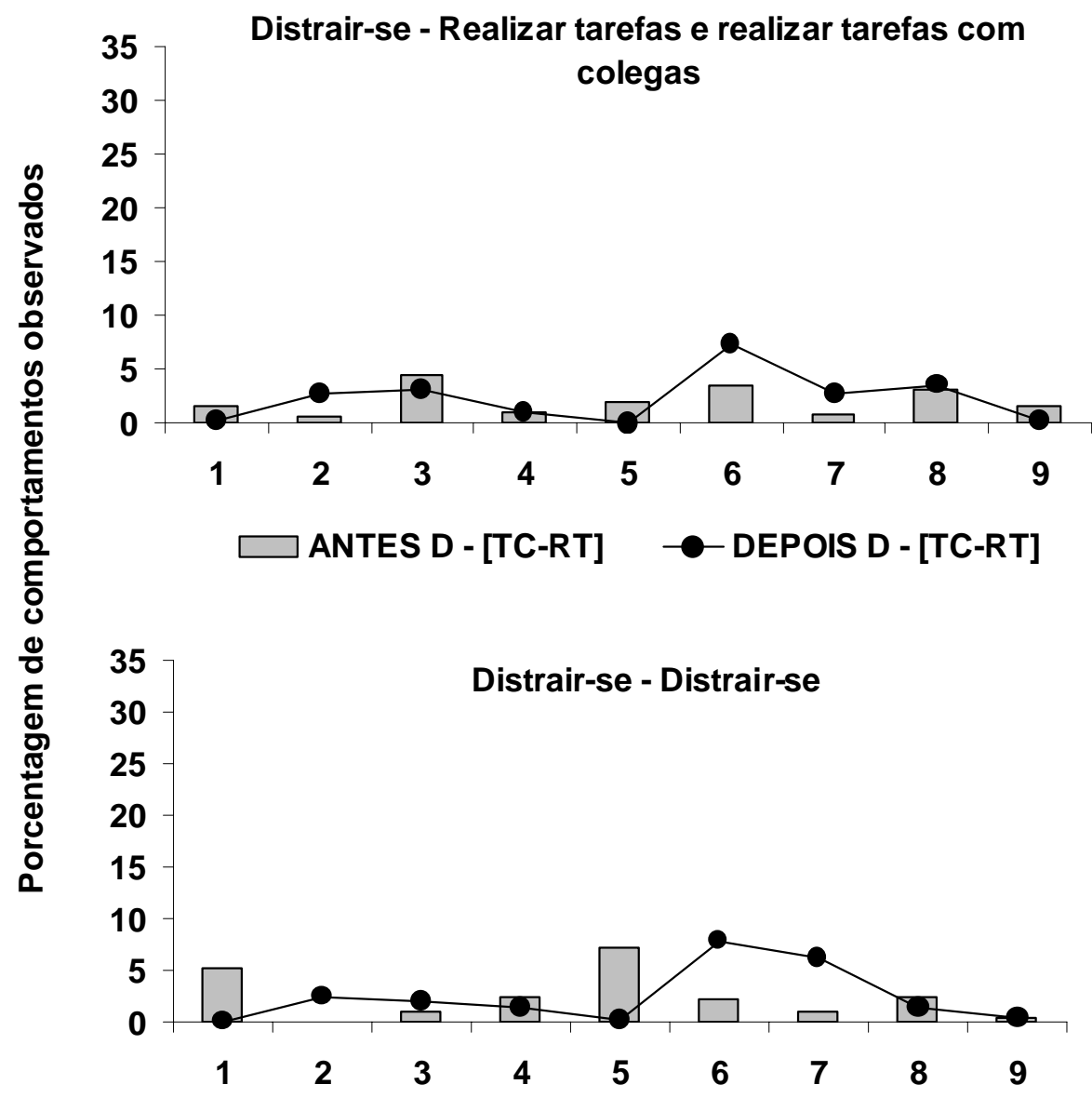

Participantes

ANTES D - D

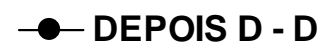

Figura 3 - Porcentagem de comportamentos não acadêmicos e acadêmicos observados na relação de: a) distrair-se (antecedente da professora) + resposta do $P$ (parte superior). Porcentagem de comportamentos não acadêmicos observados na relação de: a) distrair-se (antecedente da professora) + ação do $\mathrm{P}$ de distrair-se (parte inferior).

\section{Comportamentos acadêmicos de iniciar contato pela professora}

Pode-se observar, na Figura 4, que a resposta dos Ps à iniciativa de contato por parte da professora é bastante baixo, tanto antes como depois do procedimento, situando-se, antes do procedimento, entre 0 e 5,75\%. Dois Ps (6 e 7) responderam entre 2,5 e 5,75\%; três (P1, P2, P3 e P9) responderam entre 0,5 e $1 \%$ e os demais (P4, P5 e P8) não responderam. Após o procedimento, a porcentagem variou entre 0 e 1,25\% (para P9). Mesmo quando há explicação de tarefas pela professora (parte inferior da Figura 4), ainda assim a porcentagem de resposta individual do $\mathrm{P}$ à iniciativa de contato da professora é baixa, variando entre 0 e 4\% (para P7). É provável que haja classes de respostas diferentes de iniciativa de contato. A iniciativa, por parte do $\mathrm{P}$, pode ser unicamente de natureza social, de solicitação de atenção ou (no caso de uma classe de resposta diferente da anterior) pode ser que a iniciativa de contato por parte do $\mathrm{P}$ aumente a probabilidade de respostas de explicação de tarefas pela professora, ou seja, as condições antecedentes são diferentes e, por isso, as respostas (da professora) são, também diferentes. 


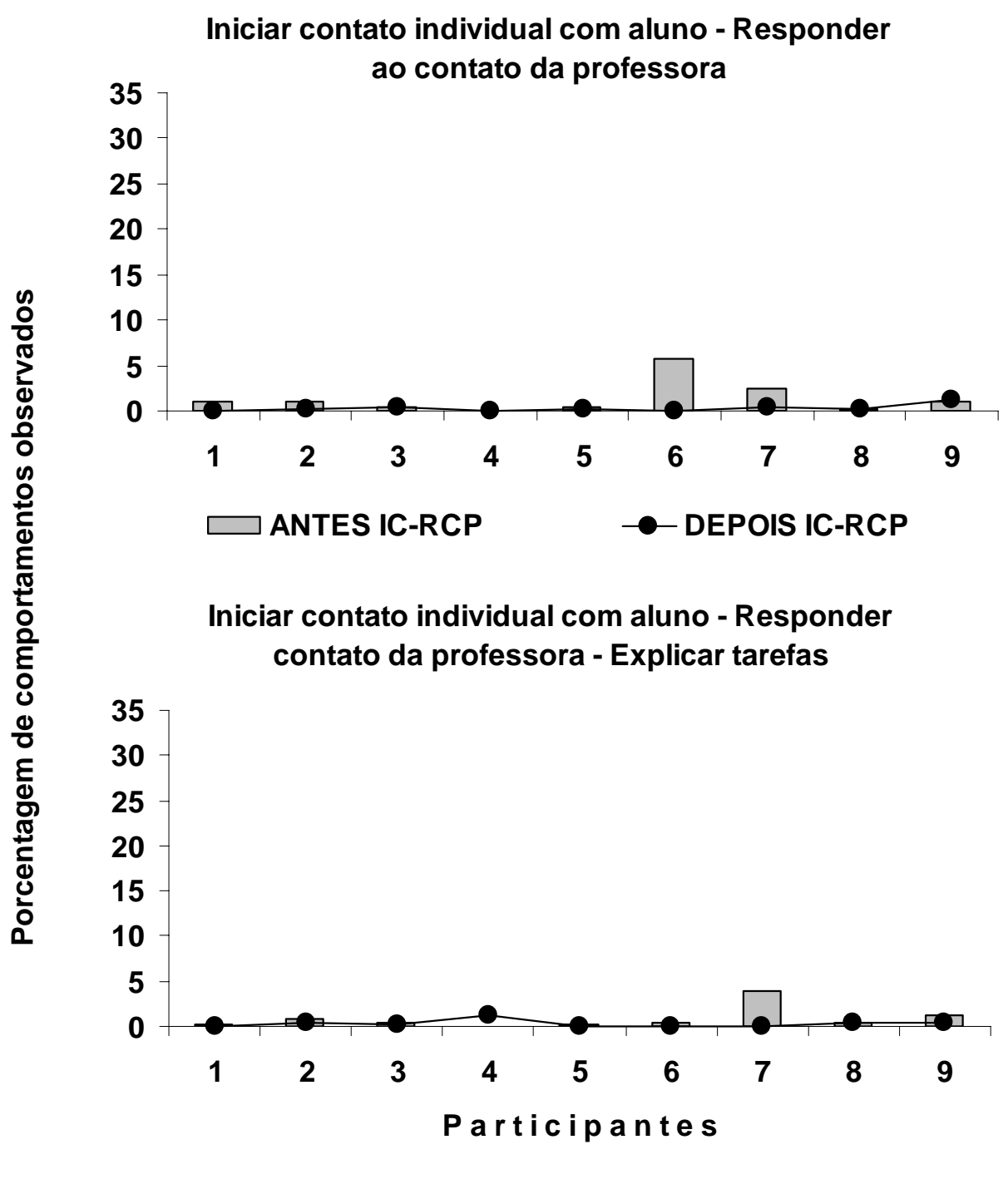

\section{ANTES IC-RCP-ET $\quad \longrightarrow$ DEPOIS IC-RCP-ET}

Figura 4 - Porcentagem resposta do $\mathrm{P}$ à iniciativa de contato por parte da professora. Na parte superior encontram-se as respostas às iniciativas da professora que não foram conseqüenciadas e, na parte inferior, as respostas às iniciativas que foram conseqüenciadas.

Os dados da Tabela 3 (lado esquerdo superior e inferior) permitem afirmar que, antes do procedimento, diante das iniciativas de contato do $\mathrm{P}$ com a professora (ICP), os incentivos (I) e repreensão (R), por parte da professora, foram baixos (0,03 de média e 0 de mediana para os incentivos e 0,04 de média e 0 de mediana para as repreensões). Após o procedimento, os incentivos tiveram um pequeno aumento $(0,08$ de média e mediana inalterada); o mesmo ocorreu com as repreensões que, também, apresentaram um pequeno aumento (0,10 de média e mediana inalterada). Mesmo com percentual baixo, a professora incentivou, tanto quanto repreendeu um número maior de Ps após o procedimento (com aumento de 1 para 3 ). Em rela- ção ao comportamento de realizar tarefas pelos Ps (RT), a porcentagem de incentivos diminuiu após o procedimento $(0,08$ para 0,03$)$, assim como o número de Ps que receberam incentivos (de 3 para 1). Em relação à repreensão, houve um pequeno aumento percentual após o procedimento $(0,10$ para 0,15$)$, assim como em relação ao número de Ps que foram repreendidos (de 3 para 4). Pode-se afirmar que estas classes de respostas (ICP e RT) não controlaram o comportamento da professora no sentido de levá-la a incentivar (I) e nem mesmo de repreender (R) as iniciativas de contato e de realização de tarefas pelos Ps. 
Tabela 3 - Porcentagem das relações: Iniciar Contato com a Professora - Incentivar $\{$ ICP-I\}; Iniciar Contato com a Professora - Repreender $\{$ ICP-R $\}$ à esquerda da tabela. Realizar Tarefa - Incentivar $\{$ RT-I\} e Realizar Tarefa - Repreender. $\{\mathbf{R T}-\mathbf{R}\}$ à direita da Tabela

\begin{tabular}{|c|c|c|c|c|c|c|}
\hline \multicolumn{2}{|c|}{ Participantes } & ANTES & DEPOIS & \multirow{10}{*}{$\frac{\stackrel{\circ}{\varepsilon}}{\frac{\tilde{c}}{\frac{1}{\alpha}}}$} & ANTES & DEPOIS \\
\hline \multirow{7}{*}{$\begin{array}{l}\stackrel{\circ}{\varepsilon} \\
\frac{\varepsilon}{0} \\
\frac{1}{1} \\
\stackrel{0}{0}\end{array}$} & P1 & 0,25 & 0 & & 0 & 0 \\
\hline & P2 & 0 & 0 & & 0,25 & 0 \\
\hline & P3 & 0 & 0 & & 0 & 0 \\
\hline & P4 & 0 & 0,25 & & 0 & 0 \\
\hline & P5 & 0 & 0 & & 0 & 0,25 \\
\hline & P6 & 0 & 0 & & 0 & 0 \\
\hline & P7 & 0 & 0 & & 0,25 & 0 \\
\hline \multirow{16}{*}{ 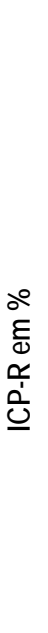 } & P8 & 0 & 0,25 & & 0 & 0 \\
\hline & P9 & 0 & 0,25 & & 0,25 & 0 \\
\hline & \multirow[t]{2}{*}{$M$} & 0,03 & 0,08 & \multirow{12}{*}{ 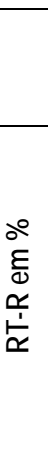 } & 0,08 & 0,03 \\
\hline & & 0,00 & & & & \\
\hline & Md & 0,00 & 0,00 & & 0,00 & 0,00 \\
\hline & P1 & 0 & 0,5 & & 0,25 & 0,25 \\
\hline & P2 & 0 & 0,25 & & 0 & 0 \\
\hline & P3 & 0 & 0 & & 0 & 0,25 \\
\hline & P4 & 0 & 0 & & 0 & 0 \\
\hline & P5 & 0 & 0 & & 0,5 & 0,25 \\
\hline & P6 & 0 & 0 & & 0 & 0 \\
\hline & P7 & 0 & 0 & & 0 & 1,25 \\
\hline & P8 & 0,5 & 0,25 & & 0,25 & 0 \\
\hline & P9 & 0 & 0 & & 0 & 0 \\
\hline & $M$ & 0,04 & 0,10 & & 0,10 & 0,15 \\
\hline & Md & 0,00 & 0,00 & & 0,00 & 0,00 \\
\hline
\end{tabular}

Os dados da Tabela 4 permitem afirmar que as iniciativas da professora de iniciar contato com os Ps e estes responderem ao contato (IC-RCP - parte superior esquerda da Tabela 4) foram percentualmente superiores antes do procedimento (média $=1,39$ e $\mathrm{md}=1,00$ ) do que ao seu final (média $=0,33$ e md $=0,25$ ). Antes do procedimento, a iniciativa do contato ocorreu com praticamente todos os Ps, exceto com P4. Após o procedimento, o contato ocorreu com apenas seis dos nove Ps. Em relação aos Ps 6 e 7, notou-se que foram eles os que mais apresentam iniciativa de contato antes do procedimento (5,75 e 2,5\% respectivamente). É provável que a mudança de uma turma com poucos para uma classe com mais alunos, como mencionado anteriormente, possa ter contribuído para a diminuição de freqüência de interação com a professora, considerando que a professora tinha dificuldade de atender individualmente aos Ps. A porcentagem de incentivos na relação IC-RCP-I foi também maior antes da aplicação do procedimento (média $=1,09$ e $\mathrm{md}=0,50$ ) do que após o seu término (média $=0,33$ e $\mathrm{md}=0,25$ ), diminuindo para todos, exceto para P4 (em que ocorreu aumento). Em relação ao número de Ps com os quais manteve contato, também diminui de 8 para 5 . Provavelmente tal relação indique que, no início do ano, a necessidade de maior atenção para o processo de aprendizagem tenha levado a professora a incentivar mais do que ao final do ano. Em relação à repreensão da resposta ao contato (IC-RCP-R), esta é praticamente nula, exceto para P1 com baixa porcentagem antes do procedimento $(0,25)$ e, para P4, após o procedimento, também com baixa porcentagem $(0,25)$.

Dentro do contexto escolar, tradicionalmente, costuma-se responsabilizar a própria criança pelas dificuldades de aprendizagem. Na melhor das hipóteses, aponta-se o contexto familiar ou o social como responsável. Porém, ignora-se, na maior parte das vezes, o fato de que ensinar e aprender constituem processos que são formados e mantidos por contingências em sala de aula, pela relação entre professor e aluno. As relações estabelecidas por cada díade professor-aluno na sala de aula são singulares, comportando uma série de contingências diferenciadas. "Para verificar e analisar o que ocorre em sala de aula entre professor e aluno, vários procedimentos podem ser utilizados, mas o de observação da interação na sala de aula permite ao pesquisador revelar as relações entre os fatos que ali estão ocorrendo desprovidos, em grande parte, de interpretações." (Viecili \& Medeiros, 2002, p. 184).

As relações que o aluno estabelece com o professor e com os próprios colegas contribuem para que ele encontre a motivação necessária para desenvolver sua capacidade e assim consiga aprender. A criança rotulada como "fracassada" tende a incorporar esse estereótipo, podendo gerar um sentimento de impotência, incapacidade e baixa auto-estima. Esses sentimentos puderam ser verificados devido à presença das pesquisadoras em sala de aula, o que permitiu uma constatação de aspectos relacionais mais subjetivos, além dos registros dos comportamentos já descritos. 
Tabela 4 - Porcentagens das relações: Responder ao Contato da Professora $\{$ IC-RCP $\}$, Responder ao Contato da Professora seguido de Incentivo\{IC-RCP-I\} à esquerda da tabela e Responder Contato da Professora seguido de Repreensão \{IC-RCP-R\} à direita da tabela

\begin{tabular}{|c|c|c|c|c|c|c|}
\hline \multicolumn{2}{|c|}{ Participantes } & \multirow{2}{*}{$\frac{\text { ANTES }}{1}$} & \multirow{2}{*}{$\begin{array}{c}\text { DEPOIS } \\
0\end{array}$} & \multirow{2}{*}{\multicolumn{2}{|c|}{$\begin{array}{c}\text { ANTES } \\
0,25\end{array}$}} & \multirow{2}{*}{$\begin{array}{c}\text { DEPOIS } \\
0\end{array}$} \\
\hline \multirow{8}{*}{ 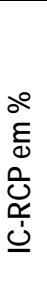 } & P1 & & & & & \\
\hline & $\mathrm{P} 2$ & 1 & 0,25 & \multirow{8}{*}{ 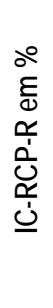 } & 0 & 0 \\
\hline & P3 & 0,5 & 0,5 & & 0 & 0 \\
\hline & P4 & 0 & 0 & & 0 & 0,25 \\
\hline & P5 & 0,5 & 0,25 & & 0 & 0 \\
\hline & P6 & 5,75 & 0 & & 0 & 0 \\
\hline & P7 & 2,5 & 0,5 & & 0 & 0 \\
\hline & P8 & 0,25 & 0,25 & & 0 & 0 \\
\hline \multirow{14}{*}{$\begin{array}{l}\stackrel{0}{0} \\
\frac{\varepsilon}{0} \\
\frac{0}{0} \\
\frac{\mathbb{d}}{0} \\
\underline{0}\end{array}$} & P9 & 1 & 1,25 & & 0 & 0 \\
\hline & $M$ & 1,39 & 0,33 & & 0,03 & 0,03 \\
\hline & Md & 1,00 & 0,25 & & 0,00 & 0,00 \\
\hline & $\mathrm{P} 1$ & 0,25 & 0 & & & \\
\hline & P2 & 0,75 & 0,5 & & & \\
\hline & P3 & 0,5 & 0,25 & & & \\
\hline & P4 & 0 & 1,25 & & & \\
\hline & P5 & 0,25 & 0 & & & \\
\hline & P6 & 0,5 & 0 & & & \\
\hline & P7 & 3 & 0 & & & \\
\hline & P8 & 0,5 & 0,5 & & & \\
\hline & P9 & 1,25 & 0,5 & & & \\
\hline & $M$ & 1,09 & 0,33 & & & \\
\hline & Md & 0,50 & 0,25 & & & \\
\hline
\end{tabular}

Pelas observações pôde-se perceber que as interações da professora com P5 (um P que não conseguia ler e, muitas vezes, não realizava as tarefas propostas) acabaram por ocasionar a estigmatização deste frente às outras crianças. Muitas vezes, a professora incentivava este $\mathrm{P}$ a participar das tarefas, porém sem sucesso. Em uma ocasião, a professora pediu que P5 fosse até o quadro e escrevesse a palavra "casa". Todos os Ps haviam ido até o quadro e realizaram a tarefa proposta. Nesta ocasião, a criança permaneceu alguns minutos em frente ao quadro com o giz na mão e não realizou a tarefa. A professora o incentivou, pedindo que, ao menos, tentasse. Por fim, sem obter resposta, a professora pediu que ele se sentasse. Outros exemplos como este ocorreram ao longo das observações com esta criança, bem como com P4. Em situaçõ̃es como esta, a professora acaba por conseqüenciar positivamente comportamentos indesejáveis dentro do contexto escolar, levando o aluno a um processo de desmotivação e, com isso, favorecendo a manutenção do baixo rendimento.

A partir da metade do ano, como foi mencionado anteriormente, a classe dos Ps 6 e 7 foi agregada em uma outra turma em decorrência da licença da professora vigente. Dessa forma, devido a um número elevado de alunos, muitas vezes a professora teve dificuldades de exercer seu papel de educadora. Esta, várias vezes, durante as observações, ausentava-se da sala de aula deixando os alunos sozinhos que, por conseguinte, tendiam a não realizar as tarefas propostas. É possível que a impossibilidade da professora controlar a turma numerosa tenha servido como fator desmotivador para fazer com que seus alunos, de fato, não aprendessem. Como alternativa, mantinha, na maior parte do tempo, os alunos trabalhando em grupo, o que favorecia os comportamentos de distração.

Assim como Gil (1990, 1993, 1995), através da observação direta, foi possível perceber que tanto os Ps sofrem influência das ações da professora, quanto o desempenho da professora é também influenciado pelas ações dos Ps, como mostram os dados da Tabela 4. Isso pode ser relatado, também, através da observação casual das observadoras como, por exemplo, preferência para com determinados alunos aos quais dispensou tratamento diferenciado. Essa maneira de se relacionar em sala de aula, provavelmente não percebida pela professora, pode ter favorecido a emergência de comportamentos acadêmicos nos Ps com o quais melhor se relacionava do que naqueles com os quais tinha mais dificuldades de relacionamento, propiciando a estes últimos desmotivação e ocorrência de comportamentos não acadêmicos, levando a um padrão de baixo rendimento.

Em síntese, a observação realizada em sala de aula sugere caminhos para uma possível compreensão das relações que ocorrem neste contexto e que, de fato, em alguns momentos, a relação professor-aluno mostrou-se problemática. Existe uma série de fatores, tanto subjetivos (motivação, empatia) quanto objetivos (contingências diferenciadas), que interferem no processo ensino-aprendizagem. Além desses fatores, uma política educacional mal planejada (baixos salá- 
rios, salas de aula lotadas, professores mal preparados) prejudica ainda mais o papel do educador. Porém, dentro da sala de aula, é tarefa do professor fornecer as condições necessárias para que cada aluno consiga desenvolver suas capacidades, tornando a relação professor-aluno bem sucedida, e a aprendizagem significativa mais provável de ocorrer. Ainda que a relação seja cíclica, como afirma Gil (1993, citada por Viecili \& Medeiros, 2002, p. 184), “o professor é o responsável pelo estabelecimento das condições nas quais dar-se-á o processo ensino-aprendizagem na sala de aula”.

As pesquisas que envolvem equivalência de estímulos, relacionadas à aprendizagem, em sua maioria, avaliam o comportamento dos Ps apenas no contexto experimental, deixando de avaliar se as mudanças verificadas com a aplicação do procedimento ocorreriam também em outros contextos do cotidiano dos participantes. Ou seja, demonstra-se apenas a relevância científica. Não há, em geral, dados que demonstrem a relevância social do procedimento. No presente estudo, as mudanças comportamentais ocorridas no contexto escolar podem ser explicadas por outras variáveis que não apenas pelo procedimento experimental. Apesar disso, a presente pesquisa, realizada em sala de aula, propõe e desenvolve um procedimento que visa verificar possíveis correlações entre as mudanças de comportamento observadas no procedimento experimental e aquelas observadas em sala de aula. Ou seja, propõe-se a verificar mudanças que vão além das encontradas em situações experimentais mais controladas do laboratório.

\section{REFERÊNCIAS}

D’Oliveira, M. H. (1987). Analisando a relação professor-aluno: Do planejamento à sala de aula. São Paulo: CLR Balieiro.

Fagundes, A. J. F. M. (1982). Descrição, definição e registro de comportamento. São Paulo: EDICON.

Gil, M. S. C. A. (1990). Análise funcional da relação professoraluno: Um exercício de identificação de controles recíprocos, Tese de Doutorado em Psicologia Experimental, USP. São Paulo.
Gil, M. S. C. A. (1993). Interação social na escola: Professor e aluno construindo o processo ensino-aprendizagem. Temas em Psicologia, 3, 29-38.

Gil, M. S. C. A. (1995). Revelando a competência escondida: A análise psicológica da atividade em sala de aula. Temas em Psicologia, 1, 23-32.

Goyos, C. \& Almeida, J. C. (1994). Software para pesquisa em discriminação condicional e equivalência com sujeitos humanos [Resumo]. Em Sociedade Brasileira de Psicologia (Org.), Resumos de Comunicações Científicas da XXIV Reunião Anual de Psicologia (pp. 210). Ribeirão Preto: SBP.

Matos, M. A. \& Danna, M. F. (1984). Ensinando observação: Uma introdução. São Paulo: EDICON.

Medeiros, J. G.; Konescki, G. E. \& Souza, A. P. (1993). Alternativa de alfabetização para crianças com dificuldades de aprendizagem em leitura e escrita [Resumo]. Em Pró-Reitoria de Pesquisa e Pós-Graduação / Departamento de Apoio à Pesquisa (Org.), Resumos de Comunicações Científicas do III Seminário Catarinense de Iniciação Científica (pp. 50). Florianópolis: PRPG / DAP.

Medeiros, J. G.; Baus, J.; Jeremias, A. E.; Mattos, V.; Freitas, A. N.; Sengl, C. S.; Silva, I. W.; Silva, M. H.; Monteiro, C. R.; Dutra, G. \& Franco, R. (1994a). A utilização do procedimento de discriminação condicional como estratégia para a consecução de objetivos de ensino [Resumo]. Em Sociedade Brasileira de Psicologia (Org.), Resumos de Comunicações Científicas, XXV Reunião Anual de Psicologia (pp. 515). Ribeirão Preto: SBP.

Medeiros, J. G.; Teixeira, C. M.; Cabral, C.; Silva, A. B. C. \& Brandão, L. (1994b). Observação e registro da interação professor-aluno junto a uma classe com dificuldades de aprendizagem [Resumo]. Em Sociedade Brasileira para o Progresso da Ciência (Org.), Resumos da 46 ${ }^{a}$ Reunião Anual da Sociedade Brasileira para o Progresso da Ciência (pp. 872). Vitória: SBPC.

Sidman, M. (1995). Coerção e suas implicações. (M. A. Andery \& T. M. Sério, Trad.). Campinas: Editorial Psy.

Viecili, J. \& Medeiros, J. G. (2002). A coerção em sala de aula: Decorrências de seu uso pelo professor na produção do fracasso escolar. Interação em Psicologia, 6 (2), 183-194.

Recebido: 14.10 .2003

Revisado: 01.12.2003

Aceito: 05.12.2003

Nota:

1 A utilização do procedimento de escolha de acordo com o modelo (matching to sample) na aquisição do comportamento conceitual (1993/1994).

\section{Sobre os autores:}

José Gonçalves Medeiros: Professor orientador, bolsista do CNPq (processo n. 551179/2002-3), lotado no Departamento de Psicologia da UFSC. Endereço para correspondência: Laboratório de Linguagem e Comportamento Verbal - Caixa Postal 5060, Fax: (048) 331-9751 - 88040-970 - Florianópolis, SC - Fones: (48) 331-9457 e (48) 331-8565 - e-mail: medeiros@mbox1.ufsc.br.

Analu Regis Fernandes: Bolsista PIBIC, aluna do Curso de Psicologia da UFSC.

Raquel Guedes Pimentel: Bolsista do PIBIC, aluna do Curso de Psicologia da UFSC.

Ana Carolina Seara Simone: Bolsista de IC/CNPq e aluna do Curso de Psicologia da UFSC. 